\title{
Osteochondroma of the coronoid process: A case report and review of the literature
}

\author{
TIANJUN LAN ${ }^{1,2 *}$, XIN LIU ${ }^{1,2 *}$, PEI-SHENG LIANG ${ }^{1,2}$ and QIAN TAO ${ }^{1,2}$ \\ ${ }^{1}$ Department of Oral and Maxillofacial Surgery, Guanghua School of Stomatology, Hospital of Stomatology; \\ ${ }^{2}$ Guangdong Provincial Key Laboratory of Stomatology, Sun Yat-Sen University, Guangzhou, Guangdong 510055, P.R. China
}

Received November 4, 2018; Accepted May 13, 2019

DOI: $10.3892 / \mathrm{ol} .2019 .10537$

\begin{abstract}
Osteochondroma (OC) is considered the most common tumor of the axial skeleton, although it is relatively uncommon in the craniofacial region. The present study describes an atypical case of $\mathrm{OC}$ of the coronoid process. A 34-year-old woman presented with severely limited mouth opening $(5 \mathrm{~mm})$ and swelling of the right zygoma. Cone-beam computed tomography (CBCT) revealed a mushroom-shaped outgrowth from the coronoid process to the inner surface of the zygomatic arch, forming a pseudojoint. The patient was treated with coronoidectomy via an intraoral approach. Histopathological examination revealed features suggestive of OC. Subsequently, the patient was able to open their mouth, and there was no evidence of recurrence or post-operative complications in the 21-month follow-up. A review of the literature revealed only 38 histologically proven cases of coronoid OC in the past 30 years (1989-2018). The incidence of the disease was higher in men compared with that in women (male:female, 2.17:1), and the median age at onset was 28.7 years, with a range of 5-57 years. Gradual limitation of mouth opening and facial asymmetry are the most noticeable symptoms. Water's view and submentovertex projection of the zygomatic arch may be useful in identifying the tumor and its association with the zygoma, while CT and CBCT permit a detailed visualization of the location and density of the tumor. Coronoidectomy is the preferred treatment option, and the prognosis is excellent, with no evidence of recurrence or malignant transformation.
\end{abstract}

Correspondence to: Dr Qian Tao, Department of Oral and Maxillofacial Surgery, Guanghua School of Stomatology, Hospital of Stomatology, Sun Yat-Sen University, 56 Lingyuanxi Road, Guangzhou, Guangdong 510055, P.R. China

E-mail: taoqian@mail.sysu.edu.cn

${ }^{*}$ Contributed equally

Key words: osteocondroma, coronoid process, clinical characteristics, treatment, prognosis

\section{Introduction}

Osteochondroma (OC) or osteocartilagenous exostosis, a cartilage-capped osseous lesion that protrudes from the surface of the affected bone, is the most common tumor of the axial skeleton, accounting for $35-50 \%$ of benign bone tumors, and $8-15 \%$ of bone tumors overall $(1,2)$. OC frequently arises from the long bones (3), such as the proximal metaphysis of the tibia or the distal metaphysis of the femur, and rarely occurs in the craniofacial region $(<1 \%$ of cases) $(4,5)$. The embryonic development of the mandibular condyle from cartilaginous ossification makes it the most frequent facial site of this type of tumor (5). Although extremely rare, involvements of the coronoid process (6), the posterior maxillary region (7), the maxillary sinus (8) and the body (9), symphysis (10) and ramus of the mandible (11) were also reported. Different from OCs of the long bones, craniofacial OCs occur at older ages (mean age, 36.4 years), and grow slowly long after the end of puberty (12). The etiology of the tumor is not fully understood, and the most accepted theory was hypothesized by Lichtenstein (13), which suggests that periosteum had the pluripotentiality to give rise to chondroblasts or osteoblasts, and that OC results from metaplastic change in the periosteum.

The present study reviewed the literature concerning coronoid OCs from 1989-2018 and also describes the case of a patient treated surgically and followed up for 21 months in the Hospital of Stomatology (Guangzhou, Guangdong, China). The case involved a giant $\mathrm{OC}$ on the coronoid process, and the patient presented with facial asymmetry and a limited ability to open her mouth.

\section{Case report}

A 34-year-old woman presented to the Hospital of Stomatology with progressive restriction of mouth opening over a period of 20 years and facial asymmetry with swelling in the right zygomatic region within the past 2 years. No history of trauma was reported. A physical examination revealed swelling in the right zygomatic arch region, facial asymmetry and the ability to open their mouth only $5 \mathrm{~mm}$. There were no associated temporomandibular joint (TMJ) complaints such as pain or clicking when opening their mouth.

A panoramic radiograph showed an enlarged right coronoid process (Fig. 1). Cone-beam computed tomography (CBCT) revealed a mushroom-shaped outgrowth from the 
lateral aspect of the coronoid process to the inner surface of the zygomatic arch, with outward expansion, forming a pseudojoint (Fig. 2). A diagnosis of OC of the right coronoid process was made according to the clinical and radiographic features. The patient was then scheduled for right coronoidectomy, performed through an intraoral approach as previously described $(5,14)$.

Considering that the patient suffered from a serious limitation of mouth opening, all procedures were conducted under general anesthesia via naso-tracheal intubation. The patient was taken to the operating room and, after naso-tracheal intubation, was prepped and draped for transoral incisions. An incision was made along the anterior border of the ramus to the tip of the coronoid process. The mucoperiosteal flaps were raised superiorly to the sigmoid notch and lower portion of the coronoid, and by blunt dissection, the coronoid process and the tumor were visualized. The tumor and the coronoid process were removed without difficulty using a fissure bur and a chisel.

Post-operative panoramic radiograph and CBCT showed that the tumor and the right coronoid process were totally excised (Figs. 3 and 4). The mass measured $\sim 4 \times 1.5 \times 1.5 \mathrm{~cm}$ (Fig. $5 \mathrm{~A}$ ). Histologically, the tumor showed the presence of three layers from the surface to the inside: Fibrous tissue, cartilaginous tissue and cancellous bone (Fig. 5B and C), which confirmed the diagnosis of OC. Three highly qualified pathologists made the diagnosis independently. Hematoxylin staining was performed as follows: The specimen was fixed in $4 \%$ paraformaldehyde at $4^{\circ} \mathrm{C}$ for $24 \mathrm{~h}$ and transferred to $19 \%$ ethylene diamine tetraacetic acid (EDTA) solution for decalcification at room temperature for $\sim 2$ months. After thoroughly decalcification, the specimen was then dehydrated as follows: $70 \%$ ethanol (60 min), $80 \%$ ethanol (40 $\mathrm{min}), 95 \%$ ethanol (30 min), 100\% ethanol (25 min) at room temperature, and embedded in paraffin. Following embedding, the specimen was sliced sagitally in to $7-\mu \mathrm{m}$ thick slices. The slices were deparaffinized in xylene, rehydrated in $100 \%$ ethanol, $95 \%$ ethanol, $80 \%$ ethanol and $70 \%$ ethanol for 2 min each, and then stained with hematoxylin and eosin for $1 \mathrm{~min}$, all at room temperature.

Postoperatively, the patient was able to open their mouth $36 \mathrm{~mm}$. After a follow-up period of 21 months, there was no evidence of recurrence and the patient was asymptomatic. The patient is still being followed up every 6 months, and the follow-up will be performed over an extended period.

\section{Literature review}

The present review was performed using a computer-assisted search of Medline Industries, Inc. (www.medline.com). The literature published in the English language on $\mathrm{OC}$ of the mandibular coronoid process from January 1989 to December 2018, concerning clinical characteristics, histopathological features and treatment, were reviewed. The criterion for inclusion was any case with a histopathological description or photomicrograph indicating OC. Cases were excluded if histopathological characteristics of the lesion were not shown, even those with a diagnosis of OC.

The review of the literature revealed only 39 reports of OC involving the coronoid process within the last 30 years $(5,6,15-48)$, plus the present case (Tables I and II). The median age at onset was 28.7 years (range, 5-57 years), with the largest number of cases observed in patients 20-30 years old. Men were more commonly diagnosed $(66.7 \%)$ than women. Unilateral masses were more frequently described (32 cases, $82.1 \%$ ) and a slight tendency for involvement of the left coronoid process $(51.3 \%)$ was revealed. These findings were generally in agreement with previous studies $(6,28)$.

As mentioned in several reported cases, the disease was predominately characterized by a lengthy history (ranging from 3 months to 20 years) of progressive reduction in the ability of mouth opening (37 cases, 94.9\%). Later signs included total trismus and appreciable swelling in the zygomatic region, visible as facial asymmetry (32 cases, $82.1 \%$ ). Pain was not a common symptom (4 cases, 10.3\%).

Panoramic radiography usually showed a sessile or pedunculated bony mass in the affected coronoid process. Water's view may be useful in identifying coronoid tumors and their relation to the wall of the maxillary sinus and the zygoma (25). To visualize the exact shape, location and density of the tumor, 3-dimensional CT and CBCT were performed and are considered as the 'gold standard' for an accurate diagnosis $(6,36)$. A pseudojoint formation between the mass and the protruded zygoma (Fig. 2) was observed in the majority of the cases (38 cases, 97.4\%), a condition that was first described by Oscar Jacob in 1899 and was hence termed Jacob's disease (49).

From the literature, coronoidectomy was recorded as the preferred treatment. Data on the surgical approaches were present in 38 cases, and were used as follows: Extraoral in $24.3 \%$ of cases; intraoral in $64.9 \%$ of cases and combined intra- and extraoral approaches in $10.8 \%$ cases, with the intraoral approach used most often.

Follow-up data were included in 25 of the 39 cases and showed that the prognosis of coronoid OC was excellent, with no recurrences or malignant transformations reported.

\section{Discussion}

An extensive review of the English literature within the last 30 years revealed a total of 435 patients with OC in the craniofacial region. The most frequently affected site was the mandibular condyle (384 cases, 88.3\%), followed by the coronoid process $(8.7 \%)$. However, involvement of the posterior maxillary region (7), maxillary sinus (8), and the body (9), symphysis (10) and ramus (11) of the mandible were also reported. A previous review of the literature by Sreeramaneni et al (6) identified 39 cases of coronoid OC up until December 2010, after which there were only 12 new cases reported. Reports with only photographic evidence of OC were not included in the present review.

The pathogenesis of OC has not yet been elucidated. Langenskiold (50) hypothesized that such lesions resulted from cells in the undifferentiated layer that were displaced from the epiphysis to the metaphyseal area. However, this may only explain the emergence of lesions in the condylar region. Another theory hypothesized that there were accumulations of embryonic cells at the points of tendon attachments, and that the continuous strain on tendons may stimulate the cartilaginous potential of the embryonic cells (51). The most widely accepted theory was hypothesized by Lichtenstein (13), who suggested that pluripotential cells in the periosteum have the 


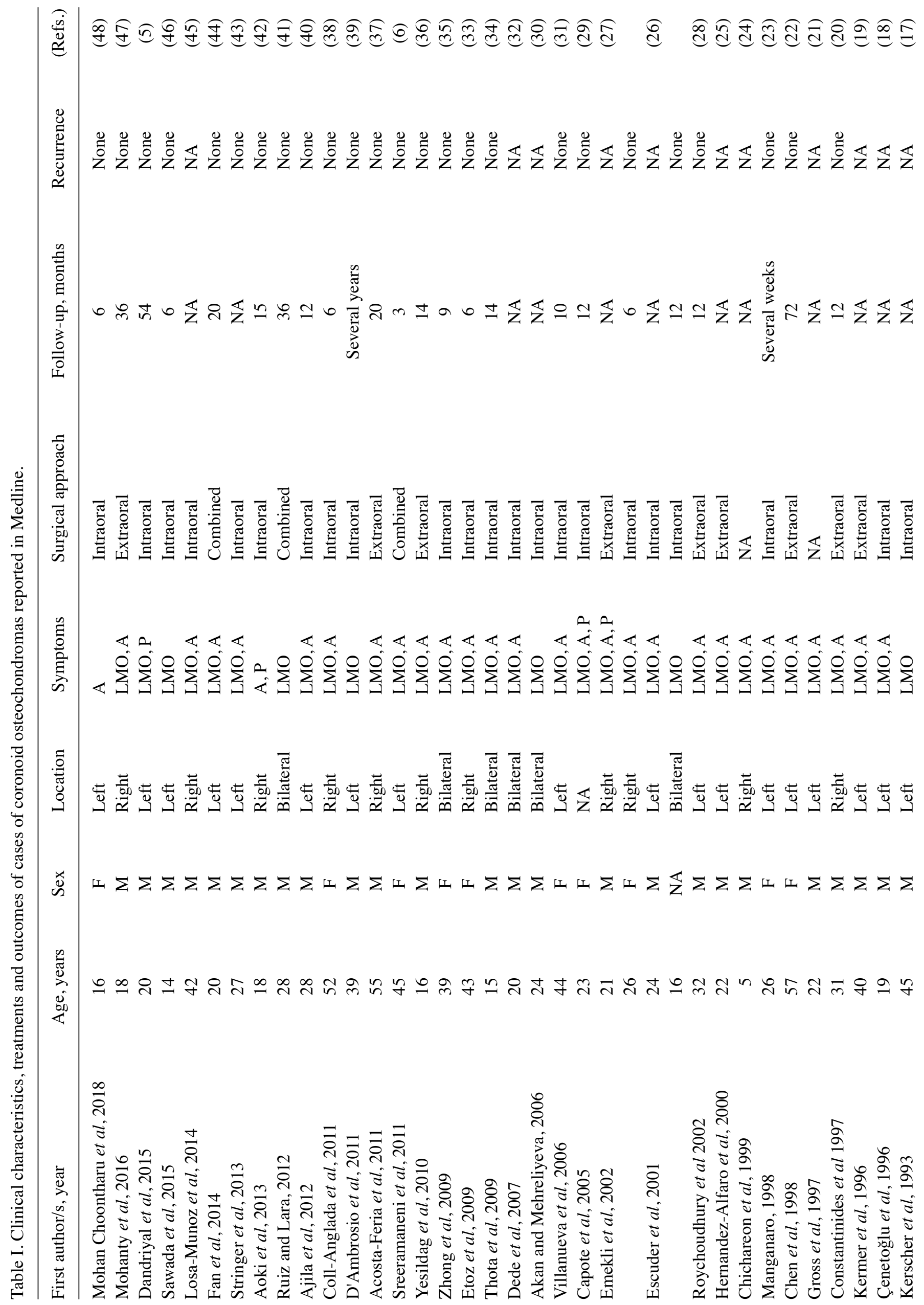


Table II. Summary of clinical features of coronoid osteochondromas.

\begin{tabular}{lc}
\hline Clinical features & Value \\
\hline Side, $\mathrm{n}(\%)$ & \\
Left & $20(51.3)$ \\
Right & $12(30.8)$ \\
Bilateral & $6(15.4)$ \\
NA & $1(2.6)$ \\
Sex, $\mathrm{n}(\%)$ & \\
Male & $26(66.7)$ \\
Female & $12(30.8)$ \\
NA & $1(2.6)$ \\
Age, years & \\
Mean & 28.7 \\
Range & $5-57$ \\
Symptoms, $\mathrm{n}(\%)$ & \\
Limitation of mouth opening & $37(94.9)$ \\
Asymmetry & $32(82.1)$ \\
Pain & $4(10.3)$
\end{tabular}

Percentage values are based on the 38 patients reviewed, and 1 case currently reported $(n=39)$.

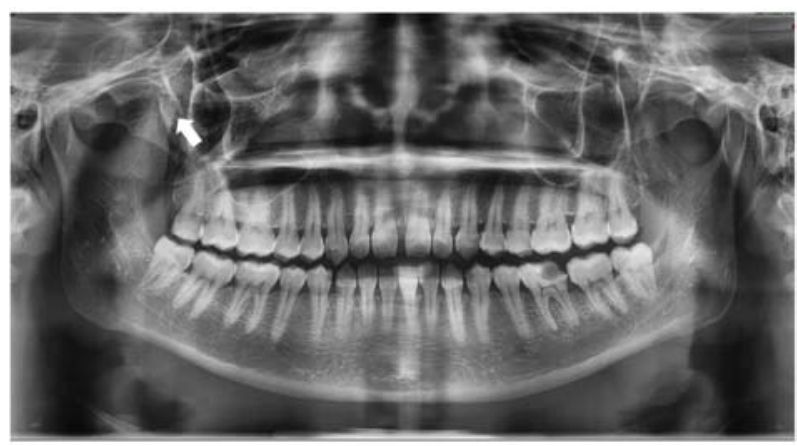

Figure 1. Panoramic radiograph revealing a bulge in the right coronoid process.

potential to form chondroblasts or osteoblasts and result in OC.

OCs can occur independently or as part of an autosomal dominant disorder known as hereditary multiple OC (HMO) syndrome (41). In the literature, of the patients with HMO syndrome, only 2 had lesions in the craniofacial region $(41,52)$. The discrimination of these two types is important, as sarcomatous changes are rare in solitary OCs (1-2\%), but do occur in $5-25 \%$ of HMO cases $(53,54)$.

Due to the rarity of its occurrence and insidious onset, $\mathrm{OC}$ arising from the coronoid process is often overlooked. A coronoid OC should be suspected when patients present with a progressively worsening ability to open their mouth and facial deformity. Due to the limitation in the ability to open the mouth, it is important to differentiate this disease from TMJ disorders or masticatory muscle tendon-aponeurosis hyperplasia (55), the latter of which is more rarely observed clinically. 


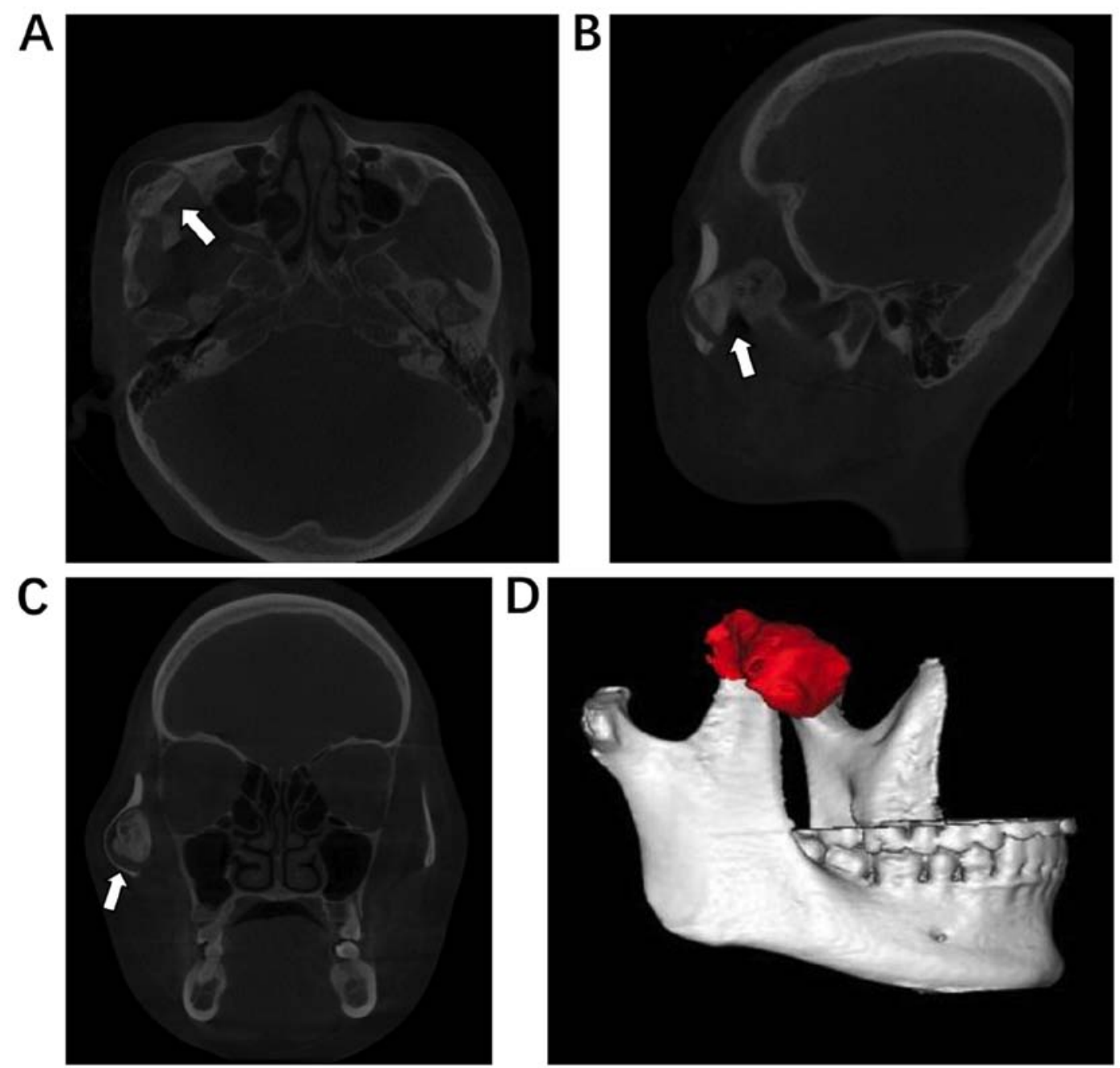

Figure 2. Preoperative $\mathrm{CBCT}$ and 3-dimensional reconstruction. $\mathrm{A}$ CBCT scan showed a mushroom-shaped mass forming a pseudojoint with the enlarged and protruded right zygoma. (A) Axial plane, (B) sagittal plane and (C) coronal plane. (D) 3-Dimensional reconstruction of the tumor and the mandible. The tumor is marked in red. CBCT, cone-beam computed tomography.

$\mathrm{CT}$ is considered as the gold standard for diagnosing $\mathrm{OC}$ and provides accurate details regarding the location of the tumor, its density and its relation to adjacent structures $(30,36)$, all of which are valuable when planning the course of treatment. However, CT exposes patients to high doses of radiation, and thus, its use should comply with appropriate guidelines. For younger patients, or those with small morphological alternations that can be clearly discerned by image examinations with less radiation exposure, the unnecessary use of CT should be prevented. Recently, CBCT, being an ideal substitute for $\mathrm{CT}$ for the diagnosis of abnormalities in the craniofacial region, has been extensively applied, owing to its lower radiation dosage. Furthermore, submentovertex projection of the zygomatic arch permits a clear visual of the coronoid tumor and the zygomatic arch, which may be more economical and less time consuming for an early diagnosis of tumors in the coronoid process.

Histologically, OC reveals the presence of bony trabeculae covered by a cartilaginous cap and fibrous tissue (56). When considering the differential diagnosis of OC, the possibilities of other lesions, such as bizarre parosteal osteochondromatous proliferations, osteoma, hyperplasia, giant cell tumors and chondroma, must also be considered $(5,57)$. Rarer bony tumors

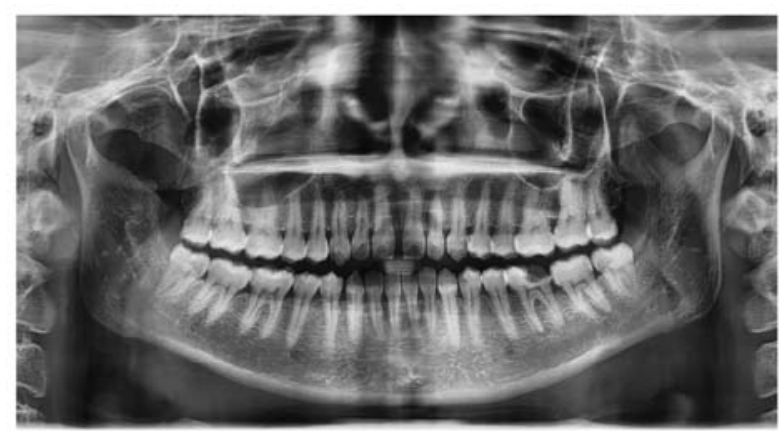

Figure 3. Postoperative panoramic radiograph showing the complete excision of the tumor and the right coronoid process.

have included chondroblastoma, osteoblastoma, chondrosarcoma, osteosarcoma and metastatic tumors (12).

Different from OCs of the long bone, the majority of which are asymptomatic and do not require any treatment (12), the functional and cosmetic problems resulting from OCs of the craniofacial bone necessitate their resection. The definitive treatment of coronoid OC is coronoidectomy. No reconstruction of the face is needed, which contrasts with the requirements for 


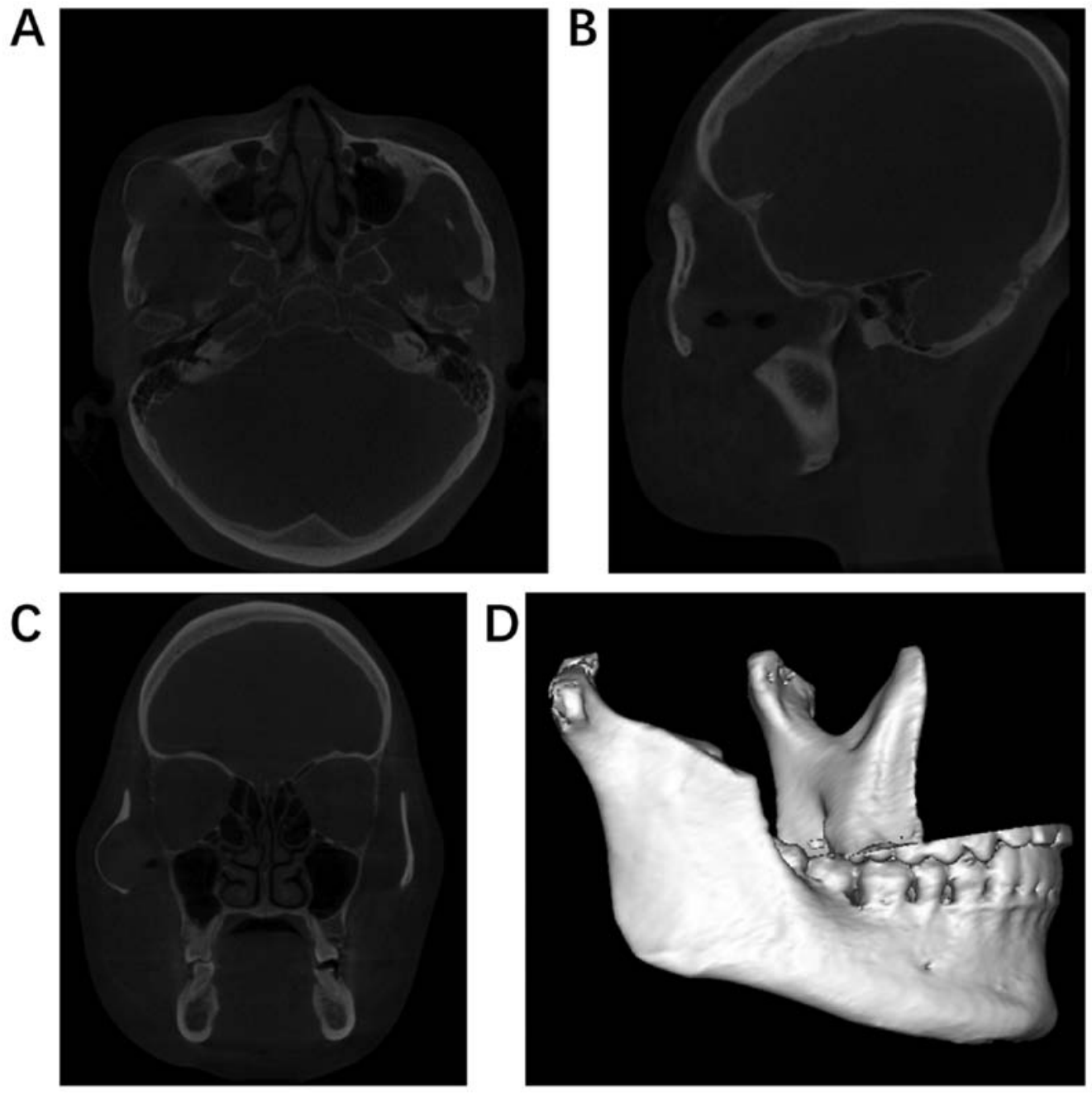

Figure 4. Postoperative CBCT and 3-dimensional reconstruction. Post-operative CBCT showed that the tumor was totally excised. (A) Axial plane, (B) sagittal plane and (C) coronal plane. (D) 3-Dimensional reconstruction of the tumor and the mandible. CBCT, cone-beam computed tomography.
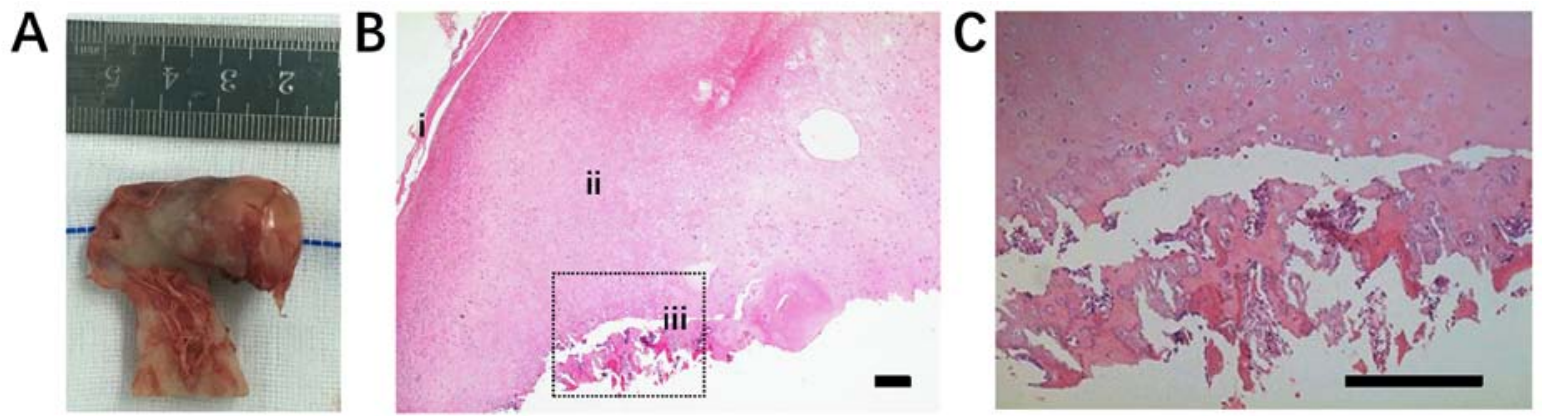

Figure 5. Excised specimen and histological hematoxylin and eosin photomicrographs. (A) The tumor measured $\sim 4.0 x 1.5 x 1.5 \mathrm{~cm}$. (B) Histologically, the mass was divided into three layers from the surface to the inside: i) Fibrous tissue; ii) cartilaginous tissue; and iii) cancellous bone. Magnification, x5. (C) Higher magnification of the region marked 'iii' in (B). Magnification, x20. Scale bar, $250 \mu \mathrm{m}$.

condylar OC. Surgical approaches primarily include intraoral and extraoral approaches, or a combination of both techniques. The intraoral approach is more favorable, as it allows direct access to the coronoid process while eliminating the potential of injuring the facial nerve and scarring (27). However, problems may occur when facing patients with severe trismus, which could prevent or hinder surgical access. Additionally, if the mass is large and in close proximity to the zygomatic arch, an extraoral approach allows better access and visualization (5). In the present case, although the tumor was extremely large and the patient presented with a serious limitation of mouth opening, considering the patient's young age and that the coronoid process was not firmly trapped in the zygomatic arch, an intraoral approach was successfully performed.

Recurrence and malignant transformations of $\mathrm{OC}$ are extremely rare $(5,12)$. For OCs in the craniofacial region, only 
6 recurrences $(12,58-62)$ and 2 malignant transformations (63) were reported. All cases with recurrence of malignant change were associated with OCs in the extracoronoid region and were initially treated in a conservative way, namely local resection of the tumor. The excellent prognostic outcome of treating patients with coronoid OCs may be due to the relatively radical surgical procedure in which the tumor, as well as the coronoid process, are removed. These findings suggest that a complete resection of the tumor should be ensured to prevent recurrence or malignant change.

In conclusion, a diagnosis of coronoid OC should be taken into consideration when facing patients with a limited ability to open their mouth, especially in patients with no other symptoms. CT or CBCT scans may serve an important role in an accurate diagnosis. Timely treatment can prevent possible complications such as facial swelling and asymmetry. Coronoidectomy is the ideal treatment. The prognosis of the disease is excellent, as no recurrence or malignant changes were reported.

\section{Acknowledgements}

Not applicable.

\section{Funding}

The present study was funded by The Science and Technology Planning Project of Guangzhou, China (grant no. 2015100110268).

\section{Availability of data and materials}

All data generated or analyzed during this study are included in this published article.

\section{Authors' contributions}

QT and XL conceived and designed the study. XL and PSL collected the data. XL and PSL wrote the manuscript. TL critically revised the article, reanalyzed the data, solved problems with the $3 \mathrm{D}$ reconstruction and edited the figures.

\section{Ethics approval and consent to participate}

Not applicable.

\section{Patient consent for publication}

Written informed consent for publication was provided by the patient.

\section{Competing interests}

The authors declare that they have no competing interests.

\section{References}

1. Dahlin DC and Unni KK: Bone tumors: General aspects and data on 8,542 cases. Thomas, 1985 .

2. Zhang J, Wang H, Li X, Li W, Wu H, Miao J and Yuan X: Osteochondromas of the mandibular condyle: Variance in radiographic appearance on panoramic radiographs. Dentomaxillofac Radiol 37: 154-160, 2008.
3. Mirra JM, Picci P and Gold RH: Bone tumors. Clinical, radiologic, and patholo-gic correlation. Investigat Radiol 26: 637, 1991.

4. Arora P, Deora SS, Kiran S and Bargale SD: Osteochondroma of condyle: Case discussion and review of treatment modalities. BMJ Case Rep 2014: pii: bcr2013200759, 2014.

5. Dandriyal R, Giri KY, Pant S, Alam S and Joshi A: Giant osteochondroma of the coronoid process. J Maxillofac Oral Surg 14 (Suppl 1): S412-S416, 2015

6. Sreeramaneni SK, Chakravarthi PS, Krishna Prasad L, Raja Satish P and Beeram RK: Jacob's disease: Report of a rare case and literature review. Int J Oral Maxillofac Surg 40: 753-757, 2011.

7. Brady FA, Sapp JP and Christensen RE: Extracondylar osteochondromas of the jaws. Oral Surg Oral Med Oral Pathol 46: 658-668, 1978.

8. Traub DJ, Marco WP, Eisenberg E and Barrows G: Osteochondroma of the maxillary sinus: Report of a case. J Oral Maxillofac Surg 48: 752-755, 1990.

9. Miyawaki T, Kobayashi M, Takeishi M, Uchida M and Kurihara K: Osteochondroma of the mandibular body. Plast Reconstr Surg 105: 1426-1428, 2000.

10. Tanaka E, Iida S, Tsuji H, Kogo M and Morita M: Solitary osteochondroma of the mandibular symphysis. Int J Oral Maxillofac Surg 33: 625-626, 2004

11. Anupam M, Shukla GK, Mishra SC, Bhatia N, Srivastava AN and Mishra N: Unusual solitary osteochondroma of the mandibular ramus. J Laryngol Otol 116: 65-66, 2002.

12. Vezeau PJ, Fridrich KL and Vincent SD: Osteochondroma of the mandibular condyle: Literature review and report of two atypical cases. J Oral Maxillofac Surg 53: 954-963, 1995.

13. Lichtenstein L: Bone tumors. Mosby, 1952.

14. Park SH, An JH, Han JJ, Jung S, Park HJ, Oh HK and Kook MS: Surgical excision of osteochondroma on mandibular condyle via preauricular approach with zygomatic arch osteotomy. Maxillofac Plast Reconstr Surg 39: 32, 2017.

15. Asanami S, Kasazaki Y and Uchida I: Large exostosis of the mandibular coronoid process. Report of a case. Oral Surg Oral Med Oral Pathol 69: 559-562, 1990.

16. Totsuka Y, Fukuda H, Iizuka T, Shindoh M and Amemiya A: Osteochondroma of the coronoid process of the mandible. Report of a case showing histological evidence of neoplasia. J Craniomaxillofac Surg 18: 27-32, 1990.

17. Kerscher A, Piette E, Tideman H and Wu PC: Osteochondroma of the coronoid process of the mandible. Report of a case and review of the literature. Oral Surg Oral Med Oral Pathol 75: 559-564, 1993

18. Çenetoğlu S, Yavuzert R, Oygür T, Akyol G and Baran NK: Osteochondroma of the coronoid process of the mandible. Eur J Plast Surg 19: 333-334, 1996.

19. Kermer C, Rasse M, Undt G and Lang S: Cartilaginous exostoses of the mandible. Int J Oral Maxillofac Surg 25: 373-375, 1996.

20. Constantinides M, Lagmay V and Miller P: Coronoid osteochondroma of the mandible: Transzygomatic access and autogenous bony reconstruction. Otolaryngol Head Neck Surg 117: S86-S91, 1997.

21. Gross M, Gavish A, Calderon S and Gazit E: The coronoid process as a cause of mandibular hypomobility-case reports. J Oral Rehabil 24: 776-781, 1997.

22. Chen PK, Chang SC, Huang F, Chen YR, Yeow VK and Williams WG: Transzygomatic coronoidectomy through an extended coronal incision for treatment of trismus due to an osteochondroma of the coronoid process of the mandible. Ann Plast Surg 41: 425-429, 1998.

23. Manganaro AM: Osteochondroma of the coronoid process. Gen Dent 46: 92-94, 1998.

24. Chichareon V, Arpornmaeklong $\mathrm{P}$ and Donsakul N: Fibrodysplasia ossificans progressiva and associated osteochondroma of the coronoid process in a child. Plast Reconstr Surg 103: 1238-1243, 1999.

25. Hernandez-Alfaro F, Escuder O and Marco V: Joint formation between an osteochondroma of the coronoid process and the zygomatic arch (Jacob disease): Report of case and review of literature. J Oral Maxillofac Surg 58: 227-232, 2000.

26. Escuder i de la Torre O, Vert Klok E, Mari i Roig A, Mommaerts MY and Pericot i Ayats J: Jacob's disease: Report of two cases and review of the literature. J Craniomaxillofac Surg 29: 372-376, 2001.

27. Emekli U, Aslan A, Onel D, Cizmeci O and Demiryont M: Osteochondroma of the coronoid process (Jacob's disease). J Oral Maxillofac Surg 60: 1354-1356, 2002. 
28. Roychoudhury A, Gupta YK, Parkash H and Karak AK: Jacob disease: Report of a case and review of the literature. J Oral Maxillofac Surg 60: 699-703, 2002.

29. Capote A, Rodriguez FJ, Blasco A and Munoz MF: Jacob's disease associated with temporomandibular joint dysfunction: A case report. Med Oral Patol Oral Cir Bucal 10: 210-214, 2005 (In English, Spanish).

30. Akan $\mathrm{H}$ and Mehreliyeva N: The value of three-dimensional computed tomography in diagnosis and management of Jacob's disease. Dentomaxillofac Radiol 35: 55-59, 2006.

31. Villanueva J, González A, Cornejo M, Núñez C and Encina S Osteochondroma of the coronoid process. Med Oral Patol Oral Cir Bucal 11: E289-E291, 2006.

32. Dede U, Tuzuner AM and Kisnisci RS: Osteochondroma of coronoid process: Jacob's disease. Int J Oral Maxillofac Surg 36: 1101, 2007.

33. Etöz OA, Alkan A and Yikilmaz A: Osteochondroma of the mandibular coronoid process: A rare cause of limited mouth opening. Br J Oral Maxillofac Surg 47: 409-411, 2009.

34. Thota G, Cillo JE Jr, Krajekian J and Dattilo DJ: Bilateral pseudojoints of the coronoid process (Jacob disease): Report of a case and review of the literature. J Oral Maxillofac Surg 67: $2521-2524,2009$

35. Zhong SC, Xu ZJ, Zhang ZG, Zheng YH, Li TX and Su K: Bilateral coronoid hyperplasia (Jacob disease on right and elongation on left): Report of a case and literature review. Oral Surg Oral Med Oral Pathol Oral Radiol Endod 107: e64-e67, 2009.

36. Yesildag A, Yariktas M, Doner F, Aydin G, Munduz M and Topal U: Osteochondroma of the coronoid process and joint formation with zygomatic arch (jacob disease): Report of a case. Eur J Dent 4: 91-94, 2010

37. Acosta-Feria M, Villar-Puchades R, Haro-Luna JJ, Ramos-Medina B and Garcia-Solano E: Limitation of mouth opening caused by osteochondroma of the coronoid process. Oral Surg Oral Med Oral Pathol Oral Radiol Endod 112: e64-e68, 2011.

38. Coll-Anglada M, Acero-Sanz J, Vila-Masana I, Navarro-Cuéllar C, Ochandiano-Caycoia S, López de-Atalaya J and Navarro-Vila C: Jacob's disease secondary to coronoid process osteochondroma. A case report. Med Oral Patol Oral Cir Bucal 16: e708-e710, 2011.

39. D'Ambrosio N, Kellman RM and Karimi S: Osteochondroma of the coronoid process (Jacob's disease): An unusual cause of restricted jaw motion. Am J Otolaryngol 32: 52-54, 2011.

40. Ajila V, Hegde S, Gopakumar R and Babu GS: Imaging and histopathological features of Jacob's disease: A case study. Head Neck Pathol 6: 51-53, 2012.

41. Ruiz LP and Lara JC: Craniomaxillofacial features in hereditary multiple exostosis. J Craniofac Surg 23: e336-e338, 2012.

42. Aoki N, Okamura K, Niino D, Iwamoto O and Kusukawa J: Osteochondroma of the right coronoid process (Jacob disease): A case report. Cranio 31: 66-69, 2013.

43. Stringer DE, Chatelain KB and Tandon R: Surgical treatment of Jacob's disease: A case report involving an osteochondroma of the coronoid process. Case Rep Surg 2013: 253740, 2013.

44. Fan H, Lv X, Shi J, Hu J and Luo E: One-stage treatment to osteochondroma of the coronoid process and secondary facial asymmetry with coronoidectomy and reduction malarplasty: A case report and literature review. J Oral Maxillofac Surg 72: 1870.e1-1870.e13, 2014

45. Losa-Muñoz PM, Burgueño-García M, González-Martín-Moro J and Sánchez-Burgos R: Osteochondroma of coronoid process: A rare etiology of Jacob disease. Craniomaxillofac Trauma Reconstr 7: 306-309, 2014.

46. Sawada K, Schulze D, Matsumoto K, Hirai S, Hashimoto K and Honda K: Osteochondroma of the coronoid process of the mandible. J Oral Sci 57: 389-392, 2015.
47. Mohanty S, Gupta H, Dabas J and Kumar P: Osteochondroma of maxillofacial region: Tumor arising from two different developmental bones. J Oral Maxillofac Pathol 20: 329, 2016.

48. Mohan Choontharu M, Buch SA, Babu GS, Castelino RL, Rao S and Rao K: A rare clinical presentation of an osteochondroma of coronoid process of mandible. J Dent (Shiraz) 19: 325-330, 2018.

49. Jacob O: Une cause rare de constriction permanente des machoires. Bull Et Mem De La Societe Anatomique De Paris 1: 917-919, 1899.

50. Langenskiöld A: The development of multiple cartilagenous exostosis. Acta Orthod Scandinav 38: 259-266, 1967.

51. Geshickter CF: Tumors of Bone (edition 3). Philadelphia, PA, Saunders, 1963

52. Navaneetham A, Rao KA, Kumaran S and Baweja HH: A unique case of multiple osteochondroma: Mandibular symphysis and femur. Ann Maxillofac Surg 2: 182-184, 2012.

53. Bovee JV, Sakkers RJ, Geirnaerdt MJ, Taminiau AH and Hogendoorn PC: Intermediate grade osteosarcoma and chondrosarcoma arising in an osteochondroma. A case report of a patient with hereditary multiple exostoses. J Clin Pathol 55: 226-229, 2002.

54. Staals EL, Bacchini P, Mercuri M and Bertoni F: Dedifferentiated chondrosarcomas arising in preexisting osteochondromas. J Bone Joint Surg Am 89: 987-993, 2007.

55. Yoda T, Sato T, Abe T, Sakamoto I, Tomaru Y, Omura K, Hatano N, Takato T and Ishii Y: Long-term results of surgical therapy for masticatory muscle tendon-aponeurosis hyperplasia accompanied by limited mouth opening. Int J Oral Maxillofac Surg 38: 1143-1147, 2009.

56. Kung'u A: Tumours of bone and cartilage. East Afr Med J 55: $572-578,1978$.

57. Kamble V, Rawat J, Kulkarni A, Pajnigara N and Dhok A: Osteochondroma of bilateral mandibular condyle with review of literature. J Clin Diagn Res 10: TD01-TD02, 2016.

58. Wolford LM, Mehra P and Franco P: Use of conservative condylectomy for treatment of osteochondroma of the mandibular condyle. J Oral Maxillofac Surg 60: 262-268, 2002.

59. Peroz I, Scholman HJ and Hell B: Osteochondroma of the mandibular condyle: A case report. Int J Oral Maxillofac Surg 31: 455-456, 2002.

60. Kwon YE, Choi KS, An CH, Choi SY, Lee JS and An SY: Recurrent osteochondroma of the mandibular condyle: A case report. Imaging Sci Dent 47: 57-62, 2017.

61. Wolford LM, Movahed R, Dhameja A and Allen WR: Low condylectomy and orthognathic surgery to treat mandibular condylar osteochondroma: A retrospective review of 37 cases. J Oral Maxillofac Surg 72: 1704-1728, 2014.

62. Ealla KK, Reddy SV, Gadipelly S and Charan C: Osteochondroma of the palate: An interesting and an unusual case presentation. J Oral Maxillofac Pathol 18: 303-307, 2014.

63. Xu B, Shi H, Wang S, Wang P and Yu Q: Secondary chondrosarcoma in the mandibular condyle. Dentomaxillofac Radiol 40: 320-323, 2011.

This work is licensed under a Creative Commons Attribution-NonCommercial-NoDerivatives 4.0 International (CC BY-NC-ND 4.0) License. 